\title{
KAJIAN DAMPAK PENINGKATAN KEBISINGAN AKIBAT OPERASINALISASI JALUR GANDA KERETA API (STUDI KASUS PEMBANGUNAN JALAN KA PARTIAL DOUBLE TRACK BREBES - LOSARI - CIREBON)
}

\author{
Evi Setiawati \\ Jurusan Teknik Elektro Fakultas Teknik Universitas Semarang
}

\begin{abstract}
ABSTRAK
Jalur Brebes - Losari - Cirebon diklasifikasikan sebagi klas 1 sesuai klasifikasi track PT. KAl seperti ditentukan didalam Keputusan Perhubungan Menteri No KM 52 tahun 2000. Pengoperasian jalan kereta api akan dilaksanakan segera setelah pembangunan jalur ganda selesai dilaksanakan, dimulai dengan pemasangan rambu - rambu lalu lintas atau tanda peringatan di perlintasan sebidang. Dengan beroperasinya jalur ganda, maka ruang manfaat jalur kereta api diperuntukkan bagi pengoperasian kereta api dan merupakan daerah yang tertutup untuk umum.

Saat dilakukan survei lapangan, tingkat kebisingan (Lsm) yang terukur dilokasi studi berkisar antara 38,7 $d B A$ sampai 65,0 dBA pada saat tidak ada kereta. Sedangkan bila saat kereta api lewat (intermitten) mempunyai tingkat kebisingan 61,3dBA sampai 94,2 dB. Secara keseluruhan dampak kegiatan Pengoperasian Jalur Ganda KA Lintas Cirebon - Kroya terhadap peningkatan kebisingan dapat dikategorikan sebagai dampak negatif penting (NP).
\end{abstract}

Kata Kunci : Jalur Brebes - Losari - Cirebon, jalur ganda, tingkat kebisingan

\section{Pendahuluan}

Jalur Brebes - Losari - Cirebon diklasifikasikan sebagi klas 1 sesuai klasifikasi track PT. KAl seperti ditentukan didalam Keputusan Perhubungan Menteri No KM 52 tahun 2000. Pada jalur ini akan dioperasikan kereta penumpang dan angkutan barang. Kereta penumpang utamanya kereta jarak jauh meliputi kereta eksekutif, bisnis dan ekonomi. Kereta penumpang dan barang ditarik menggunakan lokomotif diesel, seperti type CC 201 atau type CC203. Pengoperasian jalan kereta api akan dilaksanakan segera setelah pembangunan jalur ganda selesai dilaksanakan, dimulai dengan pemasangan rambu - rambu lalu lintas atau tanda peringatan di perlintasan sebidang. Dengan beroperasinya jalur ganda, maka ruang manfaat jalur kereta api diperuntukkan bagi pengoperasian kereta api dan merupakan daerah yang tertutup untuk umum. Hal tersebut dipertegas dengan pemberian tanda, sehingga tidak dimanfaatkan untuk kegiatan lain.

Kapasitas lintas perjalanan kereta api lintas Brebes - Losari - Cirebon pada kondisi eksisting adalah 65 kereta api dalam 24 jam. Diharapkan dengan beroperasinya jalur ganda Brebes - Losari - Cirebon dapat meningkatkan kapasitas lintas perjalanan kereta api. Berikut ini adalah perkiraan kapasitas lintas antara Stasiun Brebes sampai Stasiun Prujakan dengan dibangunnya double track;

Antara stasiun Brebes - Bulakamba $=$ $108 \mathrm{KA}$ dalam 24 jam

Antara stasiun Bulakamba - Tanjung $=$ $115 \mathrm{KA}$ dalam 24 jam

Antara stasiun Tanjung - Losari $=$ $122 \mathrm{KA}$ dalam 24 jam 
Antara stasiun Losari - Babakan $=$ $118 \mathrm{KA}$ dalam 24 jam

Antara stasiun Babakan - Waruduwur $=$ 90 KA dalam 24 jam

Antara stasiun Waruduwur - Prujakan $=$ $111 \mathrm{KA}$ dalam 24 jam

\section{Lokasi Pengambilan Sampel}

Lokasi pengambulan sampel kebisingan ditetapkan sebanyak 10 (sepuluh) titik meliputi daerah permukiman dekat rencana proyek, tempat ibadah dan sekolahan. Secara lengkap lokasi sampling disajikan pada tabel berikut ini :

Tabel 1. Lokasi Pengukuran Kebisingan

\begin{tabular}{|l|l|l|l|l|}
\hline \hline No. & Lokasi & Desa/Kel & Kecamatan & Kota/Kab \\
\hline \hline 1 & Permukiman & Brebes & Brebes & Kab. Brebes \\
\hline 2 & Permukiman & Tanjung & Tanjung & Kab. Brebes \\
\hline 3 & Permukiman & Cimohong & Bulakamba & Kab. Brebes \\
\hline 4 & Permukiman & Pabedilan Kulon & Pabedilan & Kab. Cirebon \\
\hline 5 & Permukiman & Barisan & Losari & Kab. Cirebon \\
\hline 6 & Permukiman & Jagasatru & Pekalipan & Kota Cirebon \\
\hline 7 & Stasiun & Babakan & Babakan & Kab. Cirebon \\
\hline 8 & Terbuka Hijau & Waruduwur & Pekalipan & Kota Cirebon \\
\hline 9 & Tempat ibadah & Tanjung & Tanjung & Kab. Brebes \\
\hline 10 & Sekolahan & Brebes & Brebes & Kab. Brebes \\
\hline
\end{tabular}

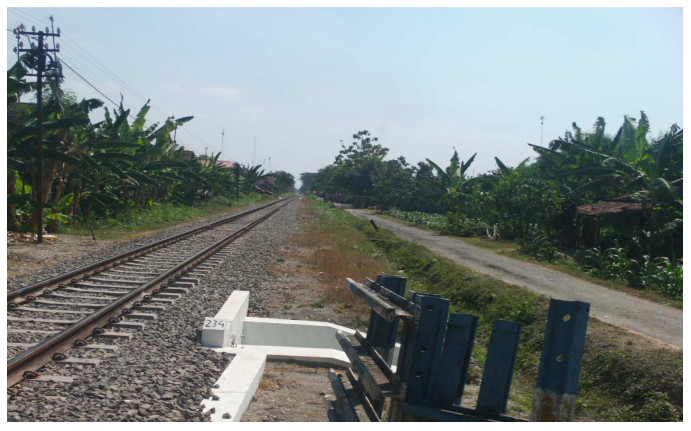

Gambar.1.Jalur Kereta Api Rel Tunggal

\section{Kebisingan}

\section{Jenis Data yang Dikumpulkan}

Data primer yang dukumpulkan adalah tingkat kebisingan kereta api saat ini (eksisting) berupa tingkat kebisingan ekuivalen $\left(L_{e q}\right)$, Tingkat kebisingan siang $\left(L_{S}\right)$, Tingkat kebisingan malam $\left(L_{M}\right)$ dan tingkat kebisingan siang-malam ( $\left.\mathrm{L}_{S M}\right)$. Sedangkan data sekunder adalah tingkat kebisingan alat/alat berat untuk konstruksi dan alat angkut material.

\section{Pengumpulan Data}

Sumber kebisingan utama yaitu pergerakaan kereta api. Dengan demikian dilakukan pengukuran tingkat kebisingan ekivalen karena kebisingannya terjadi dalam interval waktu yang singkat, tidak menerus tetapi dengan tingkat kebisingan yang tinggi. Tingkat kebisingan diukur secara langsung dibeberapa lokasi yang mewakili permukiman, tempat ibadah, sekolahan dan stasiun. Pengukuran tingkat kebisingan ekivalen dilakukan sesuai dengan jadwal kereta yang lewat dan pada saat tidak ada kereta lewat pada lokasi yang telah ditentukan.

Pengukuran tingkat kebisingan menggunakan sebuah sound level meter yang mempunyai fasilitas pengukuran $\mathrm{L}_{T M 5}$ yaitu Leq dengan waktu ukur setiap 5 detik, dilakukan pengukuran selama 10 (sepuluh) menit. Waktu pengukuran dilakukan selama aktivitas 24 jam $\left(L_{S M}\right)$ yang dibagi dalam interval waktu malam yaitu pukul 22.00$06.00\left(L_{M}\right)$ dan interval waktu siang yaitu pukul 06.00-22.00 $\left(\mathrm{L}_{\mathrm{S}}\right)$ sebagai berikut :

- $\quad \mathrm{L}_{1}$ diambil pada jam 07.00, mewakili interval jam $06.00-09.00$ 
- $\quad \mathrm{L}_{2}$ diambil pada jam 10.00, mewakili interval jam 09.00 - 14.00

- $\quad \mathrm{L}_{3}$ diambil pada jam 15.00, mewakili interval jam 14.00 - 17.00

- $\quad \mathrm{L}_{4}$ diambil pada jam 20.00, mewakili interval jam $17.00-22.00$

- $\quad \mathrm{L}_{5}$ diambil pada jam 23.00, mewakili interval jam $22.00-24.00$

- $\quad \mathrm{L}_{6}$ diambil pada jam 01.00, mewakili interval jam 24.00 - 03.00

- $\quad L_{7}$ diambil pada jam 04.00, mewakili interval jam 03.00 - 06.00

- $\quad L_{1}, \ldots, L_{7}$ merupakan $L_{e q}$ pada interval waktu tertentu

Keterangan:

$L_{e q} \quad$ : Equivalent Continous Noise atau Tingkat Kebisingan Sinambung Setara ialah nilai tingkat kebisingan yang berubah-ubah (fluktuatif) selama waktu tertentu, yang setara dengan tingkat kebisingan dari kebisingan yang ajeg (steady) pada selang waktu yang sama.
$\mathrm{L}_{\text {TM5 }}: \mathrm{L}_{\text {eq }}$ dengan waktu sampling tiap 5 detik.

$\mathrm{L}_{\mathrm{s}} \quad$ : $\mathrm{L}_{\text {eq }}$ selama siang hari.

$L_{M} \quad: L_{e q}$ selama malam hari.

$\mathrm{L}_{\mathrm{SM}} \quad$ : $\mathrm{L}_{\mathrm{eq}}$ selama siang dan malam hari.

\section{Metoda Analisis data}

Untuk mengetahui apakah tingkat kebisingan sudah melampaui baku tingkat kebisingan, perlu dicari nilai $L_{S M}$ yang dihitung sebagai berikut :

$$
L_{S M}=10 \log \frac{1}{24}\left\{16.10^{0,1 L_{S}}+8.10^{0,1\left(L_{M}+5\right)}\right\} d B(A)
$$

Sementara untuk mengetahui tingkat kebisingan dari kegiatan demobilisasi peralatan dan material dilakukan dengan tinjauan pustaka (kompilasi data sekunder).

Setelah dilakukan perhitungan selanjutnya Analisis data kebisingan lingkungan dilakukan dengan cara membandingkan hasil pengukuran dengan Baku Tingkat Kebisingan Lingkungan menurut Kep-48/MENLH /11/1996 seperti tersaji pada tabel berikut.

Tabel.2. Baku Tingkat Kebisingan Kawasan

\begin{tabular}{|l|c|}
\hline \hline Peruntukan Kawasan/ Lingkungan Kegiatan & Tk. Kebisingan (dBA) \\
\hline \hline A. Peruntukan Kawasan & 55 \\
\hline 1. Perumahan dan Permukiman & 70 \\
\hline 2. Perdagangan dan Jasa & 65 \\
\hline 3. Perkantoran dan Perdagangan & 50 \\
\hline 4. Ruang Terbuka Hijau & 70,85 \\
\hline 5. I ndustri + Portable compresor & 60 \\
\hline 6. Pemerintahan dan Fasilitas Umum & 70 \\
\hline 7. Rekreasi & \\
\hline 8. Khusus & \\
\hline - Bandar Udara * & \\
\hline - Stasiun Kereta Api * & 70 \\
\hline - Pelabuhan Laut & 60 \\
\hline - Cagar Budaya & \\
\hline B. Lingkungan Kegiatan & 55 \\
\hline 1. Rumah sakit atau sejenisnya & 55 \\
\hline 2. Sekolah atau sejenisnya & 55 \\
\hline 3. Tempat ibadah atau sejenisnya & \\
\hline
\end{tabular}

Sumber : Kep-48/MENLH/11/1996

Keterangan:

*) disesuaikan dengan Ketentuan Menteri Perhubungan 


\section{Peningkatan Kebisingan}

Peningkatan kebisingan merupakan dampak primer yang bersumber dari suara lokomotif dan gesekan roda kereta api dengan rel. Intensitas kebisingan tersebut akan menurun dengan bertambahnva jarak. Saat dilakukan survei lapangan, tingkat kebisingan $\left(\mathrm{L}_{S M}\right)$ yang terukur dilokasi studi berkisar antara 38,7 dBA sampai 65,0 dBA pada saat tidak ada kereta. Sedangkan bila saat kereta api lewat (intermitten) mempunyai tingkat kebisingan 61,3dBA sampai $94,2 \mathrm{~dB}$. Hasil pengukuran tingkat kebisingan dilokasi studi jika dibandingkan dengan Nilai Ambang Batas (NAB) berdasarkan Keputusan Menteri Negara Lingkungan Hidup No. KEP-48/MNLH/ 11/1996 tentang Baku Tingkat Kebisingan, dimana NAB tingkat kebisingan untuk lingkungan perumahan sebesar $55 \mathrm{dBA}$, perdagangan dan jasa 70 dBA, rumahsakit, sekolah dan tempat ibadah $\overline{55}$ dBA, maka kondisi tingkat kebisingan dilokasi studi sebagian besar masih dibawah NAB untuk lingkungan pemukiman atau sekolah/tempat ibadah yaitu dibawah 55 dBA. Akan tetapi pada saat kereta api lewat, maka tingkat kebisingan tersebut sudah diatas NAB. Dengan beroperasinya jalur ganda peningkatan kebisingan terbsar pada saat 2 kereta api melalui lokasi tersebut, dengan peningkatan sebesar $\pm 3 d B A$ dibandingkan pada saat rel tunggal. Namun secara umum pada saat jalur ganda beropersi kebisingan yang ditimbulkan relatif sama seperti pada saat rel tunggal, hanya saja frekwensi kebisingan yang meningkat mengingat jumlah kereta yang lewat secara bertahap akan meningkat. Waktu berlangsungya dampak akan terjadi selama 0,5 - I menit dan akan berlangsung terus menerus selama jalur ganda dioperasikan.

\section{Kesimpulan}

Berdasarkan 6 kriteria dampak, maka dampak kegiatan Pengoperasian Jalur Ganda KA Lintas Cirebon - Brebes terhadap peningkatan kebisingan dijelaskan sebagai berikut :

- Manusia yang akan terkena dampak ini tergolong banyak, yaitu penduduk yang berrnukim didekat rel kereta api Ditinjau dari manusia yang terkena dampak, maka bobot dampaknya dapat dinyatakan penting, karena manusia yang terkena dampak jumlahnya relatif banyak yaitu masyarakat sepanjang jalur ganda Cirebon - Brebes.

- Ditinjau dari persebaran dampak,

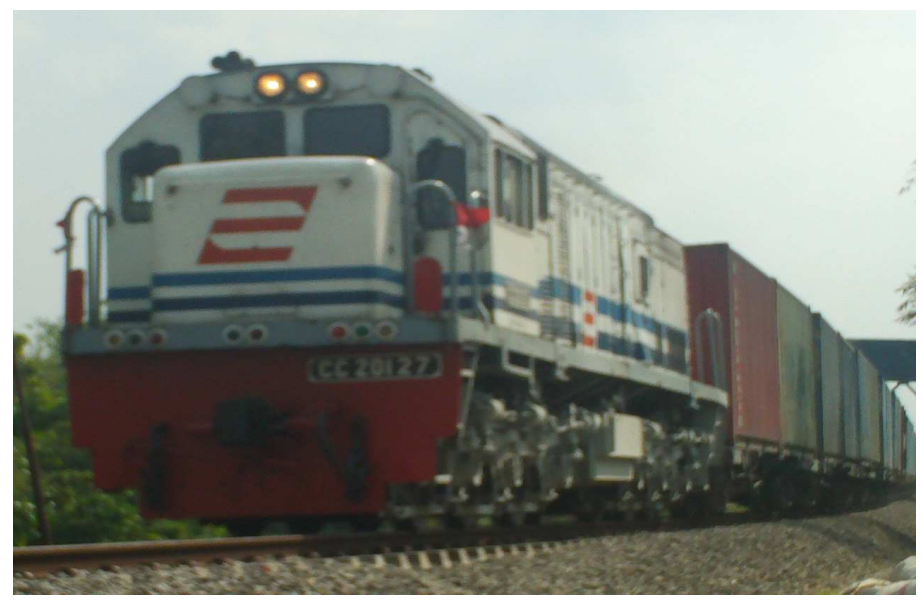

Gambar.2. Operasional Jalur Tunggal Kereta Api 
maka bobot dampaknya dapat dinyatakan penting, karena persebaran dampaknya luas, yaitu sepanjang pembangunan jalur ganda KA lintas Cirebon - Brebes.

- Ditinjau dari intensitas dampak dan lamanya dampak berlangsung, maka bobot dampaknya dapat dinyatakan penting, karena Intensitas dampak tergolong cukup tinggi dan melebihi NAB yang didasarkan pada Keputusan mentri Negara Lingkungan Hidup No.KEP-48/MENLH/11/1996 tentang Baku Tingkat Kebisingan dan dampaknya akan berlangsung selama pengoperasian jalur ganda.

- Ditinjau dari kumulatif dampak, bobot dampak dapat dinyatakan penting, karena dampak bersifat kumulatif, yaitu gangguan kenyamanan dan kesehatan diperkirakan akan terjadi selamanya, dampak ini tidak dapat dikendalikan secara preventif (dari sumber dampak) akan tetapi dapat secara kuratif (dari lin ${ }^{9}$ kungan yang terkena dampak) melalui pendekatan teknologi.

- Ditinjau dari berbalik tidaknya dampak, bobot dampak dapat dinyatakan tidak penting, karena dampak dapat berbalik.

Secara keseluruhan dampak kegiatan Pengoperasian Jalur Ganda KA Lintas Cirebon - Brebes terhadap peningkatan kebisingan dapat dikategorikan sebagai dampak negatif penting (NP).

\section{DAFTAR PUSTAKA}

E. Gaja, A.Gimenes, S. sancho and Reig, Januari 2002, Sampling Technique for Estimation of the Annual Equivalent Noise Level under Urban Traffics Conditions, jurnal Applied Acoustics vol 4 issue 1.

Eleftheriou, P,C, Januari 2002, Industrial Noise dan its Effect on Human Hearing, Jurna Applied Acoustics vol 4 issue 1.
Keputusan Menteri Negara Lingkungan Hidup, Nomor: KEP48/MENLH/11?1996 Tentang Baku Tingkat Kebisingan.

Sasongko, D,P, Hardiyanto, S,P, Hadi, S,P, AsmoroHadi, N, Subagio, A, 2000, Kebisingan Lingkungan, Badan Penerbit UNDIP, Semarang.

Team, 1999, ANDAL Pembangunan Jalur Ganda KA Lintas Cirebon-Kroya, PT Insan Mandiri, Jakarta 